Check for updates

Cite this: RSC Adv., 2019, 9, 9828

Received 10th January 2019

Accepted 23rd March 2019

DOI: 10.1039/c9ra00217k

rsc.li/rsc-advances

\title{
Facile synthesis of ordered mesoporous zinc alumina catalysts and their dehydrogenation behavior $\dagger$
}

\author{
Ming Cheng, ${ }^{\text {ab }}$ Huahua Zhao, (D) a Jian Yang, ${ }^{\text {a }}$ Jun Zhao, ${ }^{a}$ Liang Yan, ${ }^{a}$ Huanling Song *a \\ and Lingjun Chou (D) *ac
}

\begin{abstract}
Ordered mesoporous $\mathrm{Zn} / \mathrm{Al}_{2} \mathrm{O}_{3}$ materials with varying $\mathrm{Zn}$ content were simply prepared via an evaporationinduced self-assembly (EISA) method. Dehydrogenation of isobutane to isobutene was carried out on these materials; an isobutane conversion of $45.0 \%$ and isobutene yield of $39.0 \%$ were obtained over the $10 \% \mathrm{Zn} /$ $\mathrm{Al}_{2} \mathrm{O}_{3}$ catalyst at $580^{\circ} \mathrm{C}$ with $300 \mathrm{~h}^{-1} \mathrm{GHSV}$. The obtained materials with $\mathrm{Zn}$ content up to $10 \%$ possess large specific surface area and big pore volume and zinc species can be highly dispersed on the surface or incorporated into the framework. The acidity of these catalysts was changed by the introduction of $\mathrm{Zn}$, the decrease of strong acid sites is conducive to the promotion of isobutene selectivity and the weak and medium acidic sites played an important role in isobutane conversion. In addition, these catalysts exhibited good catalytic stability, due to the effective inhibition of coke formation by the ordered mesoporous structure.
\end{abstract}

\section{Introduction}

Isobutene is one of the most important raw materials and intermediates to produce butyl rubber, ETBE (ethyl tert-butyl ether), polyisobutene and other chemicals..$^{1,2}$ To better fulfill the ever-increasing market demand, a small portion of its production is by isobutane dehydrogenation. ${ }^{3}$ Currently, $\mathrm{Cr}_{2} \mathrm{O}_{3} / \mathrm{Al}_{2} \mathrm{O}_{3}$ and $\mathrm{Pt} / \mathrm{Al}_{2} \mathrm{O}_{3}$ are the two most common and employable catalysts in industrial production. ${ }^{4,5}$ However, some unavoidable drawbacks limit their further application, because Pt is expensive and has poor availability, while $\mathrm{Cr}$ is not environmentallyfriendly due to its toxicity. Therefore, the exploitation of novel catalysts with superior catalytic properties, low cost and nonpollution for isobutane dehydrogenation is highly recommendable..$^{6-8}$

At present, all kinds of metal catalysts, such as vanadiumbased, iron-based, molybdenum-based catalysts, have been widely investigated in this dehydrogenation reaction. ${ }^{9-12}$ In particular, owing to the excellent catalytic performance, $\mathrm{Zn}$ based catalysts have been interested and gazed considerably in the direct dehydrogenation of isobutane. For example, $\mathrm{Zn}$ modified HZSM-5 materials were found effective for activation of isobutane and high conversion obtained..$^{13,14}$ Unfortunately,

${ }^{a}$ State Key Laboratory for Oxo Synthesis and Selective Oxidation, Lanzhou Institute of Chemical Physics (LICP), Chinese Academy of Sciences, Lanzhou 730000, PR China. E-mail: ljchou@licp.cas.cn; songhl@licp.cas.cn

${ }^{b}$ University of Chinese Academy of Sciences, Beijing 100049, PR China

${ }^{c}$ Suzhou Research Institute of LICP, Chinese Academy of Sciences, Suzhou 215123, PR China

$\dagger$ Electronic supplementary information (ESI) available. See DOI: 10.1039/c9ra00217k the poor selectivity with respect to the formation of many undesired dry gas $\left(\mathrm{CH}_{4}\right.$ and $\left.\mathrm{C}_{2} \mathrm{H}_{6}\right)$ impeded its more broad applications, which probably derived from redundant strong acidic sites of HZSM-5 zeolite. Liu et al. reported that $27.5 \%$ isobutane conversion and $83.8 \%$ isobutene selectivity obtained in isobutane dehydrogenation over $\mathrm{Zn} / \mathrm{S}-1$ catalyst, because strong acid sites were absent. ${ }^{15}$ Moreover, $\mathrm{Zn} / \mathrm{Ti}$ thin film and $\mathrm{Zn} / \mathrm{Ga}$ oxide catalyst has also been referred in isobutane dehydrogenation..$^{16,17}$

Recently, ordered and adjustable mesoporous alumina materials have drawn research much attention. Coupled with their moderate surface acidity and good thermostability, ordered mesoporous alumina as heterogeneous catalyst support has a wonderful applying prospect. ${ }^{18}$ Morris et al. successfully synthesized $\mathrm{NiO}-\mathrm{Al}_{2} \mathrm{O}_{3}$ composites with ordered mesoporous structure and the metal oxide well dispersed on the alumina support. ${ }^{19}$ Yuan et al. reported a simple route to synthesize $\gamma-\mathrm{Al}_{2} \mathrm{O}_{3}$ using P123 template agent, which have high quality mesoporous structure. ${ }^{20}$ Schweitzer $e t$ al. put forward the computed minority catalytic pathway consists of undesired C-C bond cleavage at $\mathrm{Zn}$ (II) site had a significantly higher activation energy barrier and the high olefin selectivity observed for singlesite $\mathrm{Zn}(\mathrm{II})$ on $\mathrm{SiO}_{2} \cdot{ }^{21}$ In our previous work, well-ordered mesoporous $\mathrm{Cr}_{2} \mathrm{O}_{3} / \mathrm{Al}_{2} \mathrm{O}_{3}$ catalysts were synthesized and showed an advantage in catalytic stability. ${ }^{22}$ So far, almost no research was reported on ordered mesoporous zinc alumina composites for alkane dehydrogenation.

This study firstly prepared ordered mesoporous $x \mathrm{Zn} / \mathrm{Al}_{2} \mathrm{O}_{3}$ catalysts with different $\mathrm{Zn}$ content via evaporation-induced selfassembly (EISA) method and evaluated the catalytic performances in isobutane dehydrogenation. The textural properties 
of obtained materials were characterized by XRD analysis, $\mathrm{N}_{2}$ adsorption-desorption and TEM. And we also discussed the form of $\mathrm{Zn}$ species, metal-support interaction and surface acidity by XPS, $\mathrm{H}_{2}$-TPR and $\mathrm{NH}_{3}$-TPD. Besides, all the characterizations were associated with catalytic reactions.

\section{Experimental}

\subsection{Catalyst preparation}

Ordered mesoporous $\mathrm{Zn} / \mathrm{Al}_{2} \mathrm{O}_{3}$ materials were prepared via EISA method according to the previous literatures. ${ }^{20,23,24}$ In a typical procedure, $1.0 \mathrm{~g}$ P123 as surfactant was added to $20 \mathrm{ml}$ ethanol and the solution was stirred for $40 \mathrm{~min}$, followed by the addition of a mmol aluminum isopropoxide, $b \mathrm{mmol}$ $\mathrm{Zn}\left(\mathrm{NO}_{3}\right)_{2} \cdot 6 \mathrm{H}_{2} \mathrm{O}(a+b=10 \mathrm{mmol})$ and $1.6 \mathrm{ml}$ nitric acid. After $6 \mathrm{~h}$ of stirring, the mixed solution was transferred to a culture dish and kept in drying oven at $60{ }^{\circ} \mathrm{C}$ for two days. The obtained xerogel was calcined at $600{ }^{\circ} \mathrm{C}$ for $5 \mathrm{~h}$. The catalysts were denoted as $x \mathrm{Zn} / \mathrm{Al}_{2} \mathrm{O}_{3}$, where the nominal molar ratio $x=(b /(a$ $+b) \times 100 \%)$.

\subsection{Catalytic dehydrogenation}

The direct dehydrogenation of isobutane was studied in fixedbed quartz reactor. Typically, $900 \mathrm{mg}$ of catalyst was sieved at 60-80 mesh. The reaction temperature was set at $560-620{ }^{\circ} \mathrm{C}$. The reactant gas was fed by gas hourly space velocity (GHSV) of $300 \mathrm{~h}^{-1}$. The composition of the gaseous products was analyzed on-line using gas chromatography fitted with flame ionization detector (FID) and thermal conductivity detector (TCD).

\subsection{Characterization}

$\mathrm{N}_{2}$ adsorption-desorption isotherms were measured by Autosorb-iQ analyzer. The specific surface area was calculated by Brunauer-Emmett-Teller (BET) equation and pore size distribution was calculated by Barret-Joyner-Halenda (BJH) equation from the $\mathrm{N}_{2}$ sorption isotherm.

$\mathrm{X}$-ray diffraction (XRD) were collected on X'Pert Pro diffraction instrument using $\mathrm{Cu} \mathrm{K} \alpha$ radiation over the range $0.6^{\circ}<2 \theta<$ $5^{\circ}$ and $5^{\circ}<2 \theta<80^{\circ}$.

Transmission electron microscopy (TEM) images were conducted at TECNAIG ${ }^{2}$ F20 instrument.

X-ray photoelectron spectroscopy (XPS) were recorded on Thermon ESCALAB 250xi spectrometer. The binding energies were calibrated against at $284.8 \mathrm{eV}$ of C1s.

$\mathrm{H}_{2}$ temperature-programmed reduction $\left(\mathrm{H}_{2}-\mathrm{TPR}\right)$ was performed on ChemBET Pulsar Analyzer. Prior to the tests, sample was pretreated at $300{ }^{\circ} \mathrm{C}$ in He flow for $30 \mathrm{~min}$. After cooling to ambient temperature, then raised temperature to $650{ }^{\circ} \mathrm{C}$ in $10 \%$ $\mathrm{H}_{2}-\mathrm{Ar}$ mixed flow.

$\mathrm{NH}_{3}$ temperature-programmed desorption ( $\mathrm{NH}_{3}$-TPD) was recorded on ChemBET Pulsar analyzer combining with mass spectroscopy. After being pretreated at $300{ }^{\circ} \mathrm{C}$ in He flow, the sample adsorbed $\mathrm{NH}_{3}$ to saturation at $120{ }^{\circ} \mathrm{C}$. The profile was detected from $50{ }^{\circ} \mathrm{C}$ to $600{ }^{\circ} \mathrm{C}$.
Thermogravimetric-differential scanning calorimetry (TGDSC) was based on a NETZSCH STA 449F3 analyzer under air within $20-800{ }^{\circ} \mathrm{C}$ at $10{ }^{\circ} \mathrm{C} \mathrm{min}^{-1}$.

The $\mathrm{Zn}$ content in a series of $x \mathrm{Zn} / \mathrm{Al}_{2} \mathrm{O}_{3}$ catalysts were measured by inductively coupled plasma optical emission spectrometer (ICP-OES, 725-ES, Agilent).

\section{Results and discussion}

\subsection{XRD analysis}

The XRD patterns of all the as-synthesized $x \mathrm{Zn} / \mathrm{Al}_{2} \mathrm{O}_{3}$ materials are presented in Fig. 1. As displayed from Fig. 1A inside, a distinct reflection peak was observed in $3-10 \% \mathrm{Zn} / \mathrm{Al}_{2} \mathrm{O}_{3}$ samples at the characteristic reflection (100) of $p 6 \mathrm{~mm}$ space group, which confirming that these materials were composed of a well ordered mesoporous structure. ${ }^{25}$ With further increasing $\mathrm{Zn}$ content to $15 \%$, the diffraction peak at $0.8^{\circ}$ became almost disappeared, indicating the significant effect of zinc content in building the ordered mesoporous structure. Part B of Fig. 1 presents the wide-angle XRD patterns of all the materials, which revealed the existence of amorphous $\mathrm{Al}_{2} \mathrm{O}_{3}$. Only the $15 \% \mathrm{Zn} / \mathrm{Al}_{2} \mathrm{O}_{3}$ sample exhibited sharp diffraction peaks associated with hexagonal crystalline $\mathrm{ZnO}$ (no. 89-1397 from the ICDD). The average size of these $\mathrm{ZnO}$ particles is $23.8 \mathrm{~nm}$. On the contrary, no diffraction peaks for $\mathrm{Zn}$ species came into sight in $3-10 \% \mathrm{Zn} / \mathrm{Al}_{2} \mathrm{O}_{3}$ materials with ordered mesopore, implying $\mathrm{Zn}$ species highly dispersed on support surface or incorporated into amorphous alumina framework. ${ }^{26}$ In conclusion, the presence of ordered mesoporous structure played an important role in promoting the dispersion of $\mathrm{Zn}$ species on the catalyst support.

\subsection{Nitrogen adsorption-desorption analysis}

The nitrogen adsorption-desorption analysis of all the assynthesized $x \mathrm{Zn} / \mathrm{Al}_{2} \mathrm{O}_{3}$ materials is displayed in Fig. 2. Each sample but $15 \% \mathrm{Zn} / \mathrm{Al}_{2} \mathrm{O}_{3}$ exhibited typical IV type isotherm as well as $\mathrm{H} 1$ shaped hysteresis loop, implying the presence of uniform cylindrical mesoporous channel in these catalysts. ${ }^{27}$ Furthermore, the $3-10 \% \mathrm{Zn} / \mathrm{Al}_{2} \mathrm{O}_{3}$ samples possessed quite narrow pore size distribution around $9.5 \mathrm{~nm}$, while that of $15 \% \mathrm{Zn} / \mathrm{Al}_{2} \mathrm{O}_{3}$ sample was bigger (around $12.4 \mathrm{~nm}$ ). It suggested that the larger pores could be accumulated by $\mathrm{ZnO}$ particles. Table 1 listed the detailed data regarding to the textural properties of above samples. It has been observed that the specific surface area of as-synthesized $3-10 \% \mathrm{Zn} / \mathrm{Al}_{2} \mathrm{O}_{3}$ materials was similar (around $163 \mathrm{~m}^{2} \mathrm{~g}^{-1}$ ), which because $\mathrm{Zn}$ species highly dispersed on support surface or incorporated into alumina framework wouldn't lead to pore plugging. At a $\mathrm{Zn}$ content of $15 \%$, the specific surface area was only $31 \mathrm{~m}^{2}$ $\mathrm{g}^{-1}$ owing to the mesoporous structure collapsed. It has been known that a larger surface area conduced to the better dispersion of active species, thereby can provide more "accessible" active centers for the reactant gas. ${ }^{28}$ Therefore, these as-synthesized $3-10 \% \mathrm{Zn} / \mathrm{Al}_{2} \mathrm{O}_{3}$ catalysts may own preferable catalytic performance. 

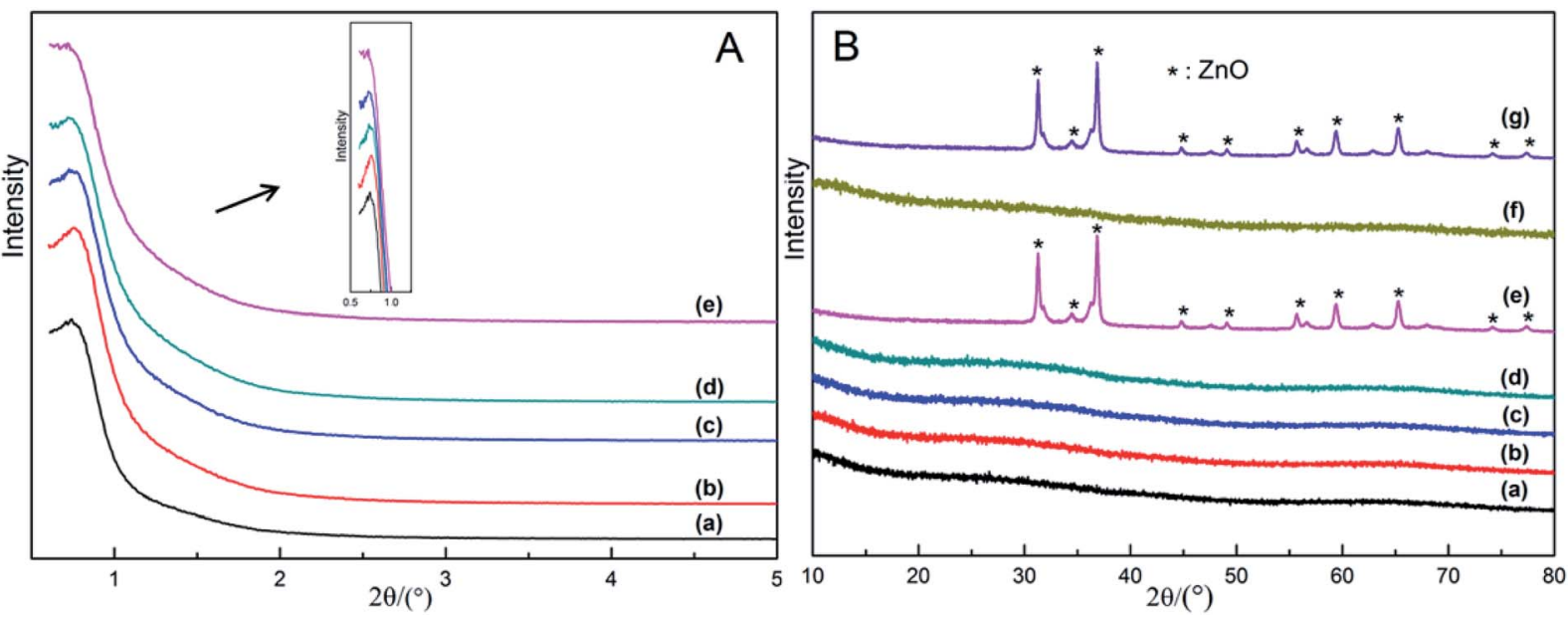

Fig. 1 The XRD patterns of the as-synthesized and spent $x \mathrm{Zn} / \mathrm{Al}_{2} \mathrm{O}_{3}$ catalysts: (a) $3 \% \mathrm{Zn} / \mathrm{Al}_{2} \mathrm{O}_{3} ;$ (b) $5 \% \mathrm{Zn} / \mathrm{Al}_{2} \mathrm{O}_{3} ;$ (c) $7 \% \mathrm{Zn} / \mathrm{Al}_{2} \mathrm{O}_{3} ;$ (d) $10 \% \mathrm{Zn} / \mathrm{Al}_{2} \mathrm{O}_{3}$; (e) $15 \% \mathrm{Zn} / \mathrm{Al}_{2} \mathrm{O}_{3}$; (f) the spent $10 \% \mathrm{Zn} / \mathrm{Al}_{2} \mathrm{O}_{3} ;$ (g) the spent $15 \% \mathrm{Zn} / \mathrm{Al}_{2} \mathrm{O}_{3}$.

\subsection{TEM analysis}

The morphology and structure of all the as-synthesized $x \mathrm{Zn} /$ $\mathrm{Al}_{2} \mathrm{O}_{3}$ materials were performed by TEM (Fig. 3). From the images, all the sample except $15 \% \mathrm{Zn} / \mathrm{Al}_{2} \mathrm{O}_{3}$ presented one dimensional parallel channel along [ $\left.\begin{array}{lll}1 & 1 & 0\end{array}\right]$, which intuitively confirmed the presence of well-ordered mesoporous structure in the $3-10 \% \mathrm{Zn} / \mathrm{Al}_{2} \mathrm{O}_{3}$ catalysts. Notably, no distinct $\mathrm{ZnO}$ clusters were invisible in the images, illustrating the high dispersion of $\mathrm{Zn}$ species on the ordered mesoporous channel. This result conformed to the low-angle XRD analysis. Only a fraction of ordered mesopore was formed for $15 \% \mathrm{Zn} / \mathrm{Al}_{2} \mathrm{O}_{3}$ sample. In the EDX profile of $10 \% \mathrm{Zn} / \mathrm{Al}_{2} \mathrm{O}_{3}$ sample (Fig. 3f), the characteristic peaks of $\mathrm{Al}, \mathrm{Zn}$, O element can be observed clearly, which verified that $\mathrm{Zn}$ species had been successfully loaded. Besides, elemental mapping has further confirmed the ordered mesoporous structure and shown $\mathrm{Zn}$ species on the surface to be highly dispersed and distributed homogeneously over the $10 \% \mathrm{Zn} / \mathrm{Al}_{2} \mathrm{O}_{3}$ catalyst. However, an obvious aggregation of $\mathrm{ZnO}$ particles was visible on the surface of $15 \% \mathrm{Zn} / \mathrm{Al}_{2} \mathrm{O}_{3}$ catalyst, which conformed the result of wide-angle XRD analysis (Fig. 4).

\subsection{XPS analysis}

The XPS spectra of Zn 2p orbital for all the as-synthesized $x \mathrm{Zn} /$ $\mathrm{Al}_{2} \mathrm{O}_{3}$ materials are depicted in Fig. 5. As displayed, the binding energy located at 1021.2-1201.6 eV and 1044.3-1044.7 eV was assigned to $\mathrm{Zn}^{2+}$, as proved by spin-orbital splitting of $23.1 \mathrm{eV}$ between $\mathrm{Zn} 2 \mathrm{p}_{3 / 2}$ and $\mathrm{Zn} 2 \mathrm{p}_{1 / 2} .^{29,30}$ Noteworthy, the binding energy of $\mathrm{Zn} 2 \mathrm{p}$ in the sample $15 \% \mathrm{Zn} / \mathrm{Al}_{2} \mathrm{O}_{3}$ was lower than that of $10 \% \mathrm{Zn} / \mathrm{Al}_{2} \mathrm{O}_{3}$, which may be derived from the difference of $\mathrm{Zn}$ species in these catalysts. By deconvolution, the peak of $15 \% \mathrm{Zn} /$ $\mathrm{Al}_{2} \mathrm{O}_{3}$ was divided into two peaks, the big one may be assigned to bulk ZnO particle on the surface, another small one may belonged to $\mathrm{Zn}$ species incorporated into alumina framework. The $\mathrm{Zn}$ content calculated by XPS and ICP-OES was used to affirmed and the corresponding data listed in Table 1 . We can see that the bulk $\mathrm{Zn}$ contents were closely to the calculated data,
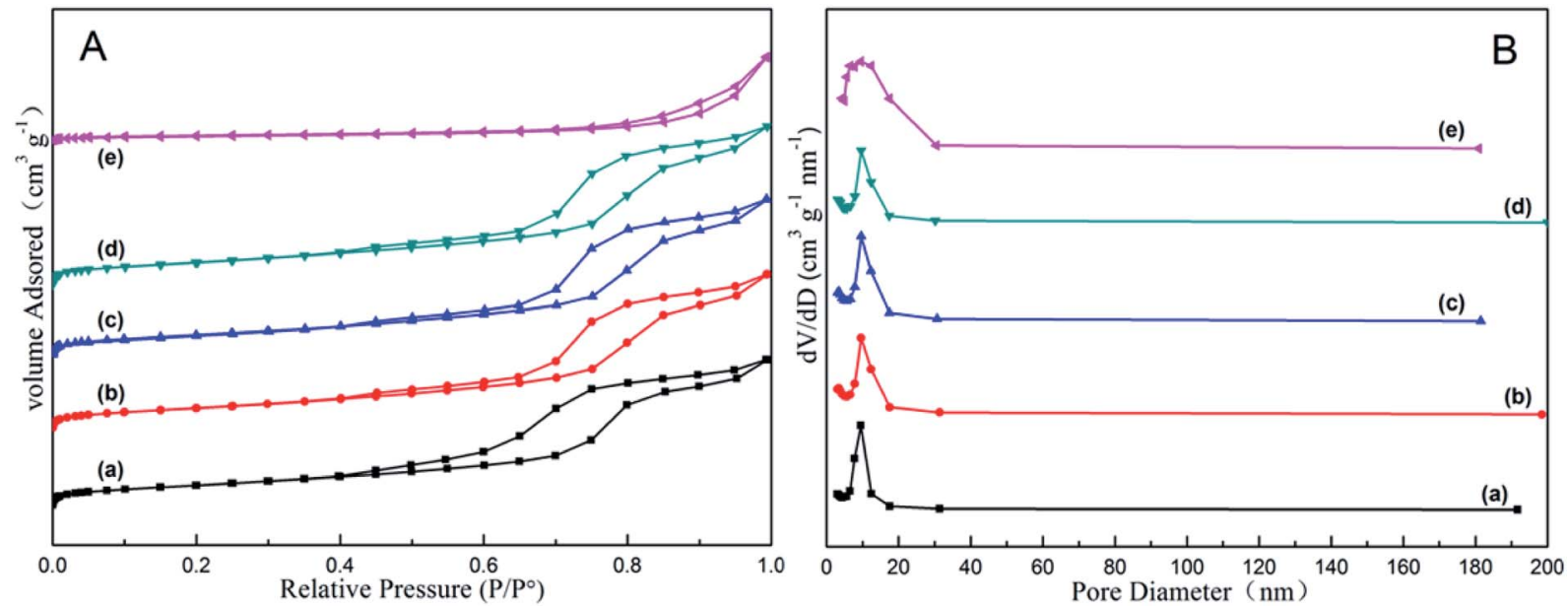

Fig. 2 The nitrogen adsorption-desorption analysis of the as-synthesized $x \mathrm{Zn} / \mathrm{Al}_{2} \mathrm{O}_{3}$ catalysts: (a) $3 \% \mathrm{Zn} / \mathrm{Al}_{2} \mathrm{O}_{3} ;$ (b) $5 \% \mathrm{Zn} / \mathrm{Al}_{2} \mathrm{O}_{3} ;$ (c) $7 \% \mathrm{Zn} / \mathrm{Al}_{2} \mathrm{O}_{3}$; (d) $10 \% \mathrm{Zn} / \mathrm{Al}_{2} \mathrm{O}_{3}$; (e) $15 \% \mathrm{Zn} / \mathrm{Al}_{2} \mathrm{O}_{3}$. 
Table 1 The textural data of the as-synthesized $x \mathrm{Zn} / \mathrm{Al}_{2} \mathrm{O}_{3}$ catalysts $^{a}$

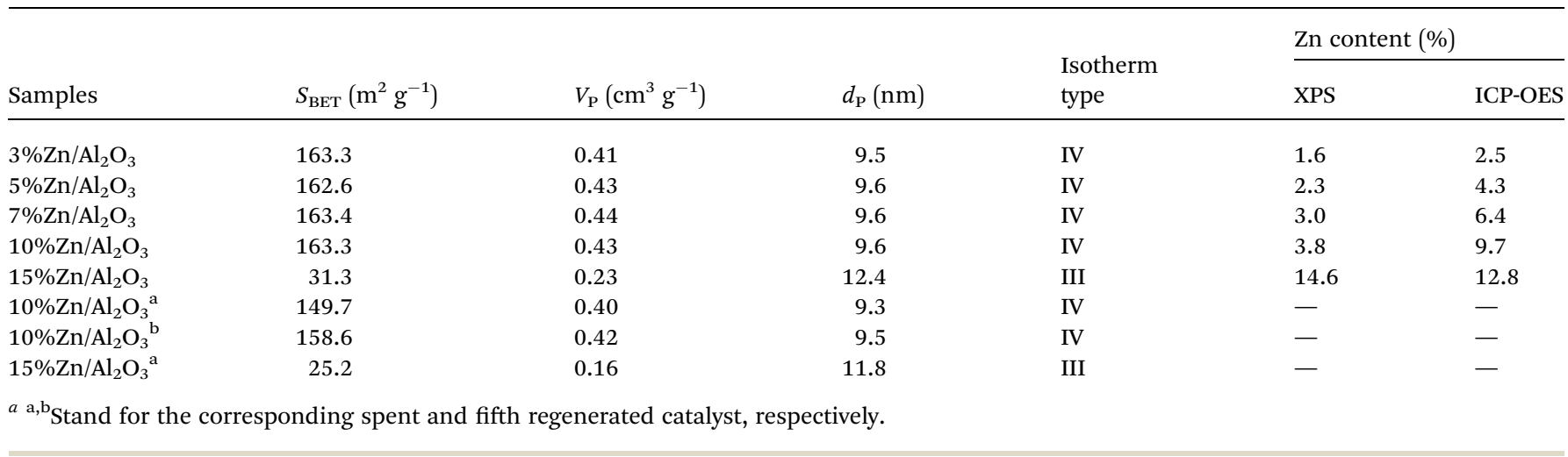

only $15 \% \mathrm{Zn} / \mathrm{Al}_{2} \mathrm{O}_{3}$ had a larger deviation. Moreover, the surface Zn content $(14.6 \%)$ of this sample from XPS was higher than the actual $\mathrm{Zn}$ content (12.8\%), suggesting aggregation of $\mathrm{ZnO}$ particles on the surface. In contrast, the surface $\mathrm{Zn}$ was less than the bulk for $3-10 \% \mathrm{Zn} / \mathrm{Al}_{2} \mathrm{O}_{3}$ samples, which was due to most of $\mathrm{Zn}$ species incorporated into alumina framework. These
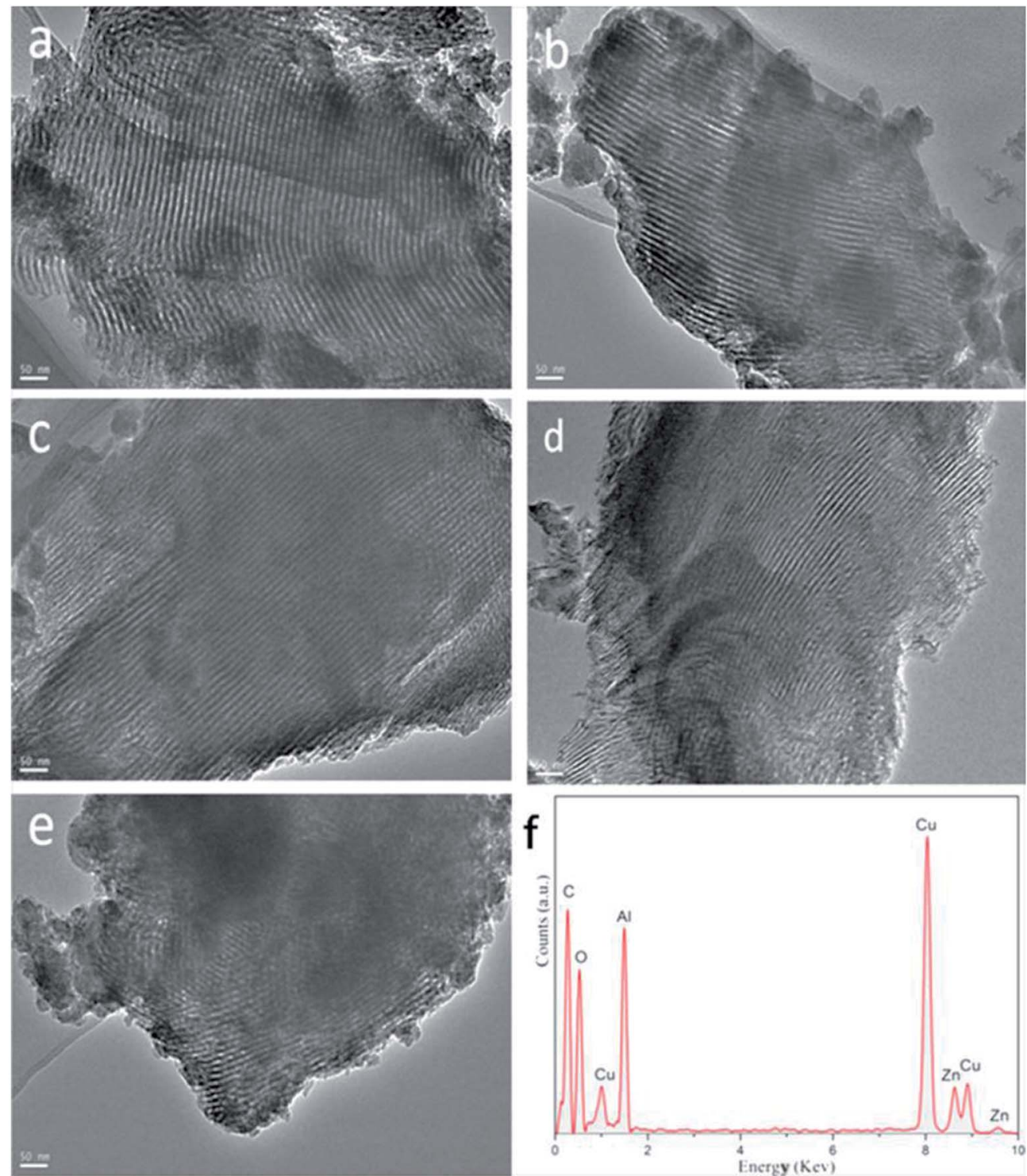

Fig. 3 The TEM images of the as-synthesized $x \mathrm{Zn} / \mathrm{Al}_{2} \mathrm{O}_{3}$ catalysts: (a) $3 \% \mathrm{Zn} / \mathrm{Al}_{2} \mathrm{O}_{3}$; (b) $5 \% \mathrm{Zn} / \mathrm{Al}_{2} \mathrm{O}_{3}$; (c) $7 \% \mathrm{Zn} / \mathrm{Al}_{2} \mathrm{O}_{3}$; (d) $10 \% \mathrm{Zn} / \mathrm{Al}_{2} \mathrm{O}_{3}$; (e) $15 \% \mathrm{Zn} /$ $\mathrm{Al}_{2} \mathrm{O}_{3}$. (f) $\mathrm{EDX}$ characterization for $10 \% \mathrm{Zn} / \mathrm{Al}_{2} \mathrm{O}_{3}$. 

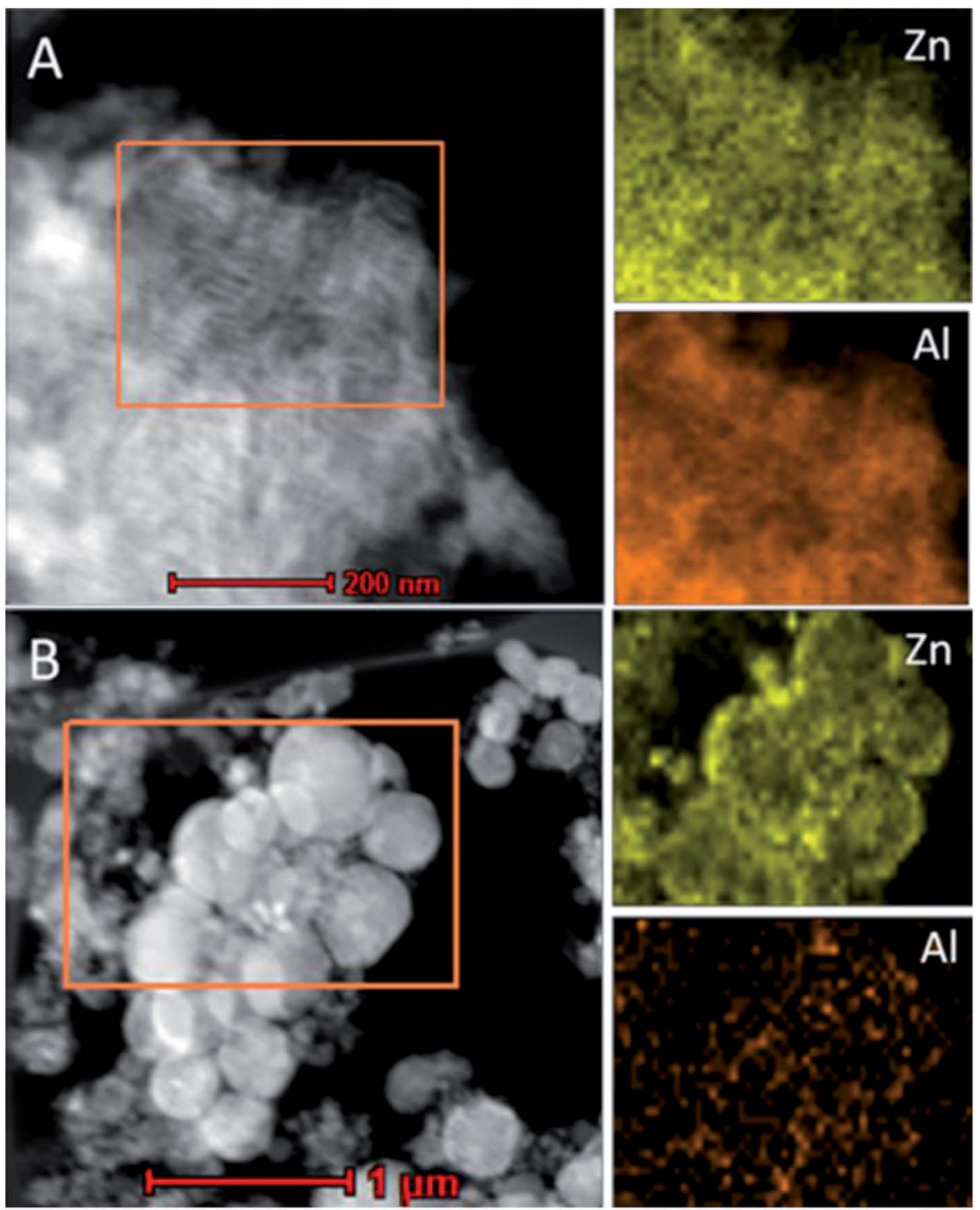

Fig. 4 TEM image and $\mathrm{Zn}$, Al elemental mappings of the fresh samples: (A) $10 \% \mathrm{Zn} / \mathrm{Al}_{2} \mathrm{O}_{3}$; (B) $15 \% \mathrm{Zn} / \mathrm{Al}_{2} \mathrm{O}_{3}$.

results were accorded with wide-angle XRD analysis and confirmed the change of $\mathrm{Zn}$ species when increased $\mathrm{Zn}$ content from $10 \%$ to $15 \%$. Besides, the higher binding energy meaning a stronger interaction between $\mathrm{Zn}$ species and support in 3-10\% $\mathrm{Zn} / \mathrm{Al}_{2} \mathrm{O}_{3}$ catalysts. This result will be further confirmed by following $\mathrm{H}_{2}$-TPR characterization.

\section{5. $\mathrm{H}_{2}$-TPR profiles}

$\mathrm{H}_{2}$-TPR characterization is a very useful instrument to investigate the interaction between $\mathrm{Zn}$ species and catalyst support. The results for the as-synthesized $x \mathrm{Zn} / \mathrm{Al}_{2} \mathrm{O}_{3}$ materials and pure $\mathrm{ZnO}$ are shown in Fig. 6. All profiles of $x \mathrm{Zn} / \mathrm{Al}_{2} \mathrm{O}_{3}$ showed a broad reduction peak around $490{ }^{\circ} \mathrm{C}$, which could be assigned to the reduction of highly dispersed zinc species on support surface and $\mathrm{Zn}$ species incorporated into alumina framework. However, $15 \% \mathrm{Zn} / \mathrm{Al}_{2} \mathrm{O}_{3}$ catalyst presented a unique reduction peak at $416{ }^{\circ} \mathrm{C}$, which was similar with the reduction peak of pure bulk ZnO. More specifically, this peak belonged to the reduction of binuclear $(\mathrm{Zn}-\mathrm{O}-\mathrm{Zn})^{2+}$ clusters. $^{31}$ It has been known that the higher reduction temperature, the stronger interaction between metal and support. Therefore, the $\mathrm{Zn}$ species with the reduction peak around $490{ }^{\circ} \mathrm{C}$ have stronger interaction with support. ${ }^{32}$ The characterization of $\mathrm{H}_{2}$-TPR was coincided with the above XRD and XPS analysis.

\section{6. $\mathrm{NH}_{3}$-TPD analysis}

The acidic property of all the as-synthesized $x \mathrm{Zn} / \mathrm{Al}_{2} \mathrm{O}_{3}$ materials was determined by $\mathrm{NH}_{3}$-TPD and the corresponding results are displayed in Fig. S1. $\dagger$ All the samples exhibited a broad peak at 50-600 ${ }^{\circ} \mathrm{C}$, indicating abundant different intensities of acidic sites in $x \mathrm{Zn} / \mathrm{Al}_{2} \mathrm{O}_{3}$ catalysts. By deconvolution, the broad peak was divided into four peaks accredited to physically adsorbed $\mathrm{NH}_{3}$, weak, medium and strong acidic sites respectively. ${ }^{33,34}$ The detailed calculation result was in Table 2 . As displayed, all the 


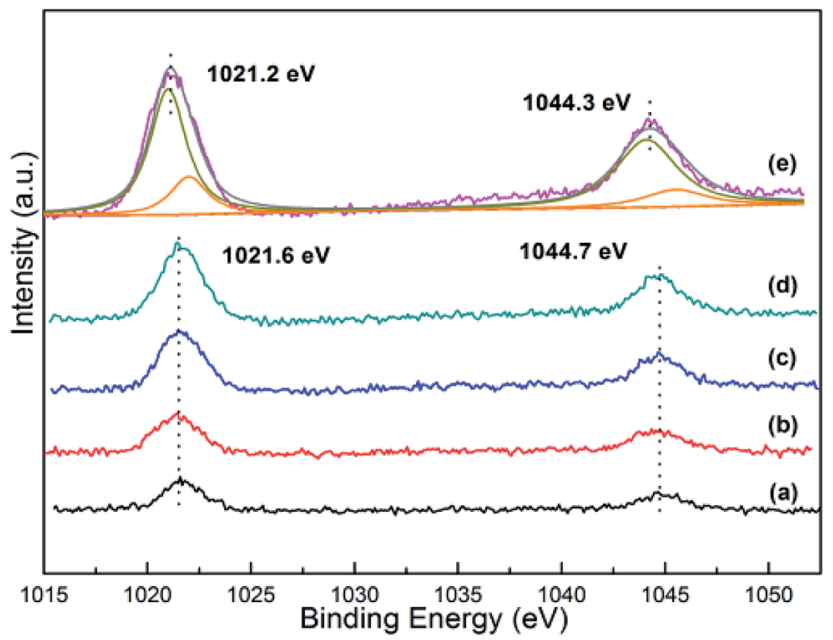

Fig. 5 The $\mathrm{Zn} 2 \mathrm{p}$ XPS spectra of the as-synthesized $x \mathrm{Zn} / \mathrm{Al}_{2} \mathrm{O}_{3}$ catalysts: (a) $3 \% \mathrm{Zn} / \mathrm{Al}_{2} \mathrm{O}_{3}$; (b) $5 \% \mathrm{Zn} / \mathrm{Al}_{2} \mathrm{O}_{3}$; (c) $7 \% \mathrm{Zn} / \mathrm{Al}_{2} \mathrm{O}_{3}$; (d) $10 \% \mathrm{Zn} /$ $\mathrm{Al}_{2} \mathrm{O}_{3}$; (e) $15 \% \mathrm{Zn} / \mathrm{Al}_{2} \mathrm{O}_{3}$.

samples except for $15 \% \mathrm{Zn} / \mathrm{Al}_{2} \mathrm{O}_{3}$ exhibited similar amount of physically adsorbed $\mathrm{NH}_{3}$, which due to their comparable pore property. However, the specific surface area and pore volume of

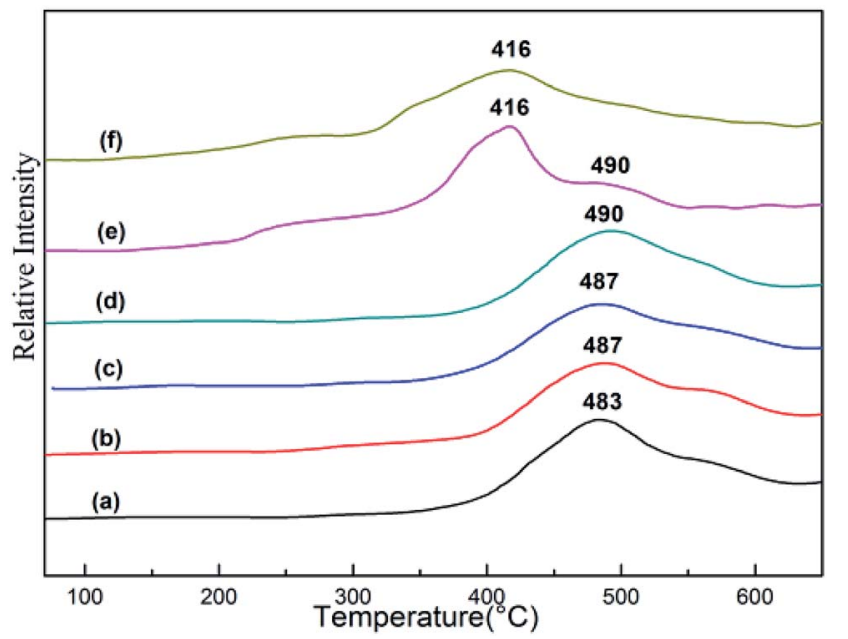

Fig. 6 The $\mathrm{H}_{2}$-TPR profiles of the as-synthesized $x \mathrm{Zn} / \mathrm{Al}_{2} \mathrm{O}_{3}$ catalysts: (a) $3 \% \mathrm{Zn} / \mathrm{Al}_{2} \mathrm{O}_{3}$; (b) $5 \% \mathrm{Zn} / \mathrm{Al}_{2} \mathrm{O}_{3}$; (c) $7 \% \mathrm{Zn} / \mathrm{Al}_{2} \mathrm{O}_{3}$; (d) $10 \% \mathrm{Zn} / \mathrm{Al}_{2} \mathrm{O}_{3}$; (e) $15 \% \mathrm{Zn} / \mathrm{Al}_{2} \mathrm{O}_{3}$; (f) $\mathrm{ZnO}$.
$15 \% \mathrm{Zn} / \mathrm{Al}_{2} \mathrm{O}_{3}$ was much smaller, then physically adsorbed $\mathrm{NH}_{3}$ also less than other samples. Besides, we can see that there are three different acidic sites on pure ordered mesoporous $\mathrm{Al}_{2} \mathrm{O}_{3}$. With the introduction of $3 \% \mathrm{Zn}$, the amount of three acidic sites significantly enhanced. It indicated that a part of three types acid sites originated from surface hydroxyl group and coordinative unsaturated $\mathrm{Al}$ sites on $\mathrm{Al}_{2} \mathrm{O}_{3}$ support, and other derived from $\mathrm{Zn}$ species. ${ }^{15,35}$ Note that the total and weak acidic sites gradually increased, while the strong acidic sites decreased slowly with the increase of Zn content until $10 \%$. When the Zn content reached $15 \%$, the total acidic strength of this catalyst declined sharply, which may due to bulk ZnO has rarely acidic sites (Fig. S2 $\dagger$ ). It was well established that weak and medium acid sites played a key role to isobutane conversion in dehydrogenation reaction. ${ }^{15}$ However, side reactions (polymerization, isomerization and cracking) are mainly catalyzed by strong acid sites. ${ }^{36}$ As a conclusion, the various $x \mathrm{Zn} / \mathrm{Al}_{2} \mathrm{O}_{3}$ catalysts with the different number of acidic sites may present distinct catalytic performance.

\subsection{Catalytic performance in the isobutane dehydrogenation}

The reactivity of isobutane dehydrogenation over a series of $x \mathrm{Zn} / \mathrm{Al}_{2} \mathrm{O}_{3}$ catalysts is displayed in Fig. 7 . As we can notice that the catalytic activity of $x \mathrm{Zn} / \mathrm{Al}_{2} \mathrm{O}_{3}$ catalysts gradually increased until $10 \% \mathrm{Zn}$ content. The $10 \% \mathrm{Zn} / \mathrm{Al}_{2} \mathrm{O}_{3}$ catalyst exhibited a notably higher initial isobutane conversion (46.6\%) and initial isobutene selectivity $(81.8 \%)$ by contrast with the $3 \% \mathrm{Zn} / \mathrm{Al}_{2} \mathrm{O}_{3}$ (29.4\% conversion and $69.4 \%$ selectivity), indicating that $\mathrm{Zn}$ content was a very significant factor in isobutane dehydrogenation reaction. In addition to this, with increasing reaction time, the reactivity over the $3-10 \% \mathrm{Zn} / \mathrm{Al}_{2} \mathrm{O}_{3}$ catalysts can basically hold steady, while the $15 \% \mathrm{Zn} / \mathrm{Al}_{2} \mathrm{O}_{3}$ catalyst presented poor catalytic stability.

Isobutane dehydrogenation is an endothermic reaction in thermodynamics, which need relatively high temperature to obtain excellent isobutene yield. The effect of reaction temperature on catalytic activity of $10 \% \mathrm{Zn} / \mathrm{Al}_{2} \mathrm{O}_{3}$ catalyst was investigated in Fig. 8. The conversion of isobutane was $45.0 \%$ and the selectivity of isobutene was $86.7 \%$ at $580{ }^{\circ} \mathrm{C}$ after $30 \mathrm{~min}$. With the increase of the reaction temperature, the conversion of isobutane obviously increased and selectivity of isobutene significantly decreased, which was quite conformed to the characteristic of alkane dehydrogenation reaction. However, the

Table 2 The acidic properties of the as-synthesized $\mathrm{Al}_{2} \mathrm{O}_{3}$ and $x \mathrm{Zn} / \mathrm{Al}_{2} \mathrm{O}_{3}$ catalysts

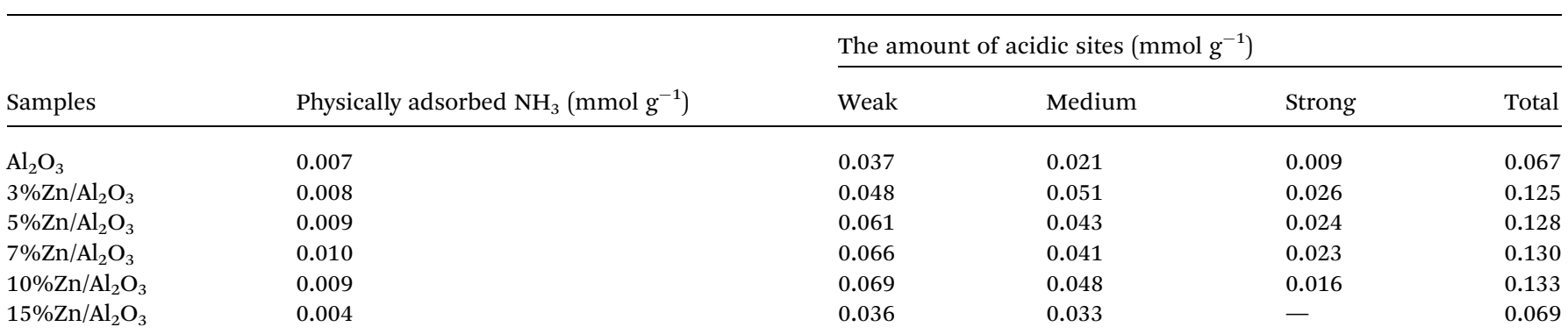




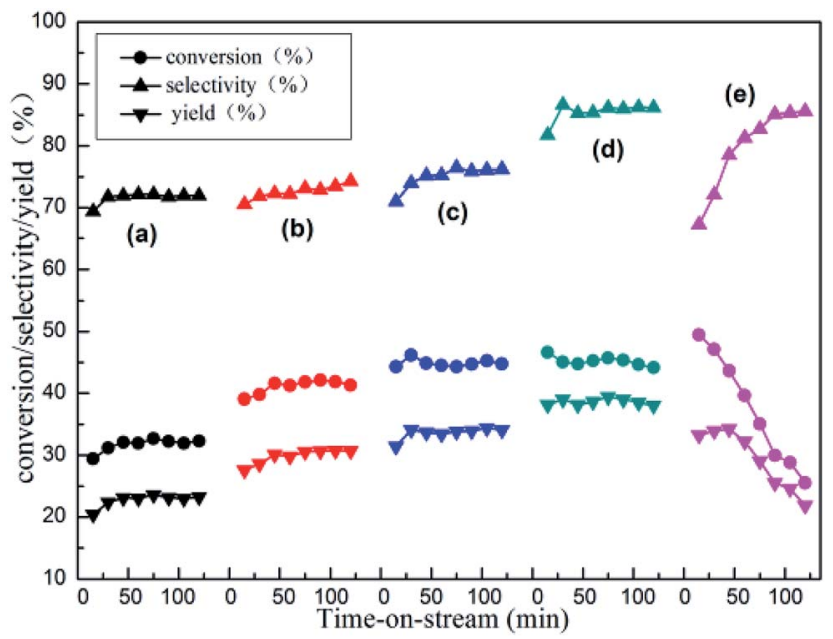

Fig. 7 The reactivity of isobutane dehydrogenation over the assynthesized $x \mathrm{Zn} / \mathrm{Al}_{2} \mathrm{O}_{3}$ catalysts: (a) $3 \% \mathrm{Zn} / \mathrm{Al}_{2} \mathrm{O}_{3}$; (b) $5 \% \mathrm{Zn} / \mathrm{Al}_{2} \mathrm{O}_{3}$; (c) $7 \% \mathrm{Zn} / \mathrm{Al}_{2} \mathrm{O}_{3}$; (d) $10 \% \mathrm{Zn} / \mathrm{Al}_{2} \mathrm{O}_{3}$; (e) $15 \% \mathrm{Zn} / \mathrm{Al}_{2} \mathrm{O}_{3}$. Reaction condition: $T$ $=580{ }^{\circ} \mathrm{C}, \mathrm{GHSV}=300 \mathrm{~h}^{-1}$.

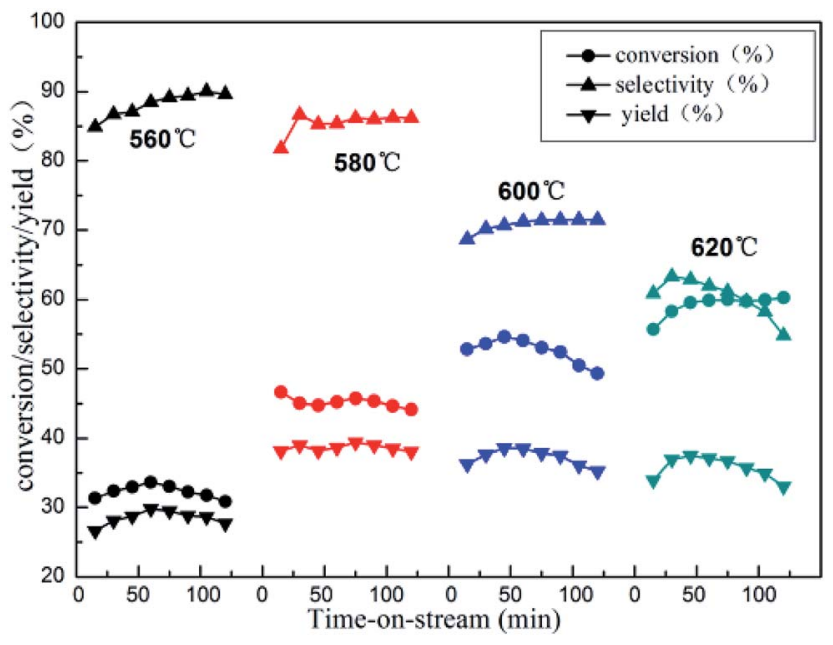

Fig. 8 The reactivity of isobutane dehydrogenation over the $10 \% \mathrm{Zn} /$ $\mathrm{Al}_{2} \mathrm{O}_{3}$ catalyst. Reaction condition: $\mathrm{GHSV}=300 \mathrm{~h}^{-1}$.

isobutane conversion dropped drastically, isobutene selectivity just increased slightly with the reaction temperature decreased to $560{ }^{\circ} \mathrm{C}$. In view of catalytic stability, $580^{\circ} \mathrm{C}$ was deemed as the optimal reaction temperature.

The impact of the GHSV on catalytic activity was also carefully studied over $10 \% \mathrm{Zn} / \mathrm{Al}_{2} \mathrm{O}_{3}$ catalyst (Fig. 9). As we can see, with GHSV increasing from 300 to $600 \mathrm{~h}^{-1}$, the initial isobutane conversion decreased obviously (from $46.6 \%$ to $30.6 \%$ ), while initial isobutene selectivity increased (from $81.8 \%$ to $91.1 \%$ ). As the GHSV continues to rise, it became slope that isobutane conversion decreased with time on stream.

In order to further investigate what were active sites for isobutane dehydrogenation, we tested this reaction at $580{ }^{\circ} \mathrm{C}$ over ordered mesoporous $\mathrm{Al}_{2} \mathrm{O}_{3}$ and commercial $\mathrm{ZnO}$ as a contrast (Fig. S3†). It can be seen that initial isobutane

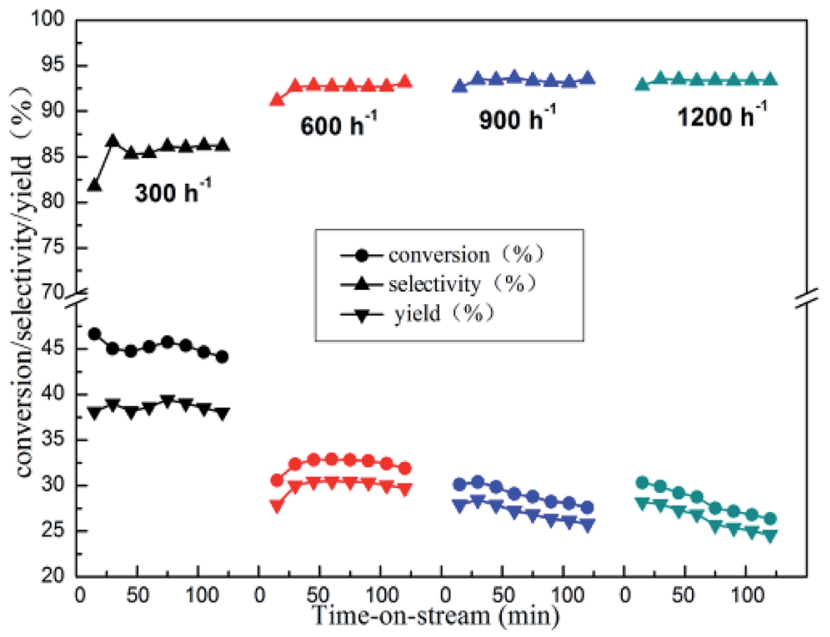

Fig. 9 The reactivity of isobutane dehydrogenation over the $10 \% \mathrm{Zn} /$ $\mathrm{Al}_{2} \mathrm{O}_{3}$ catalyst. Reaction condition: $T=580^{\circ} \mathrm{C}$.

conversion and initial isobutene yield over $\mathrm{Al}_{2} \mathrm{O}_{3}$ were only $3.1 \%$ and $2.1 \%$, which illustrated that ordered mesoporous $\mathrm{Al}_{2} \mathrm{O}_{3}$ was inactive to the reaction. $\mathrm{ZnO}$ exhibited slightly higher initial dehydrogenation activity $(9.2 \%$ isobutane conversion and $5.5 \%$ isobutene yield). It seemed that bulk $\mathrm{ZnO}$ particle had some catalytic ability. Surprisingly, with the introduction of $\mathrm{Zn}$, the $x \mathrm{Zn} / \mathrm{Al}_{2} \mathrm{O}_{3}$ catalysts exhibited very excellent initial catalytic activity, even then the ordered mesopore collapsed and $\mathrm{Zn}$ species was not highly dispersed over $15 \% \mathrm{Zn} / \mathrm{Al}_{2} \mathrm{O}_{3}$ catalyst. Considering the possibility of zinc incorporated into $\mathrm{Al}_{2} \mathrm{O}_{3}$ framework over $15 \% \mathrm{Zn} / \mathrm{Al}_{2} \mathrm{O}_{3}$ catalyst, we deduced that the existence of framework zinc may play a crucial role. However, there is no direct evidence for this. The essential role of $\mathrm{Zn}$ species of $x \mathrm{Zn} / \mathrm{Al}_{2} \mathrm{O}_{3}$ in isobutane dehydrogenation still need to be identified, which is the focus of the following work in our laboratory. In addition, it is well-known that the amount of different acidic sites of catalyst are the key to affect catalytic activity in alkane dehydrogenation reaction. ${ }^{37}$ The isobutane

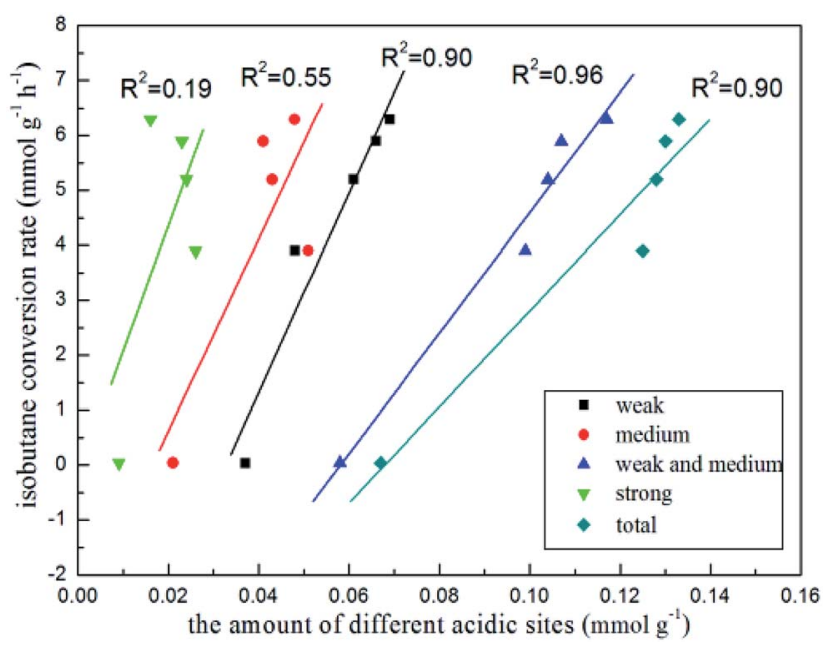

Fig. 10 The trend of isobutane conversion rate with the amount of different kinds of the acidic sites. 
conversion rate $v s$. the number of different acidic sites on the basis of Table 2 were plotted (Fig. 10). The isobutane conversion rate versus the amount of strong acidic sites showed the worst linear correlation $\left(R^{2}=0.19\right)$, nevertheless, versus the amount of weak and medium acidic sites presented the best linear correlation $\left(R^{2}=0.96\right)$, indicating that strong acidic sites were not the decisive factor for isobutane conversion, while both the weak and medium acidic sites took the important part in isobutane conversion. Besides, the isobutane selectivity was obviously increased with the decrease of the amount of strong acidic sites over $3-10 \% \mathrm{Zn} / \mathrm{Al}_{2} \mathrm{O}_{3}$ catalysts, indicated strong acid sites mainly catalyzed side reactions.

\subsection{The stability of ordered mesoporous $\mathrm{Zn} / \mathrm{Al}_{2} \mathrm{O}_{3}$ catalyst}

3.8.1. XRD analysis. The wide-angle XRD patterns of the spent catalysts are shown in Fig. 1. It was observed that there is no difference between fresh and spent catalysts. The crystalline $\mathrm{ZnO}$ phase was also visible over spent $15 \% \mathrm{Zn} / \mathrm{Al}_{2} \mathrm{O}_{3}$ catalyst, and no $\mathrm{Zn}$ species over the spent $10 \% \mathrm{Zn} / \mathrm{Al}_{2} \mathrm{O}_{3}$ catalyst as well, indicating that $\mathrm{Zn}$ species were stable without phase transformation during this dehydrogenation reaction.

3.8.2. Nitrogen adsorption-desorption analysis. The nitrogen adsorption-desorption analysis of the spent and regenerated catalysts are in Fig. $\mathrm{S} 4 . \dagger$ Compared with the corresponding fresh catalysts, the isotherms of spent catalysts had no obvious changed and still presented uniform pore size. The textural properties are presented in Table 1 . It was clearly seen that the BET specific surface areas of the spent $10 \% \mathrm{Zn} / \mathrm{Al}_{2} \mathrm{O}_{3}$ and $15 \% \mathrm{Zn} / \mathrm{Al}_{2} \mathrm{O}_{3}$ catalysts were greatly reduced to $149.7 \mathrm{~m}^{2} \mathrm{~g}^{-1}$ and $25.2 \mathrm{~m}^{2} \mathrm{~g}^{-1}$, respectively. It was probably due to that coke deposition on the spent catalyst blocked a portion of the pore, thus leading to the decrease of textural performance. After five dehydrogenation-regeneration cycles, the slightly diminished
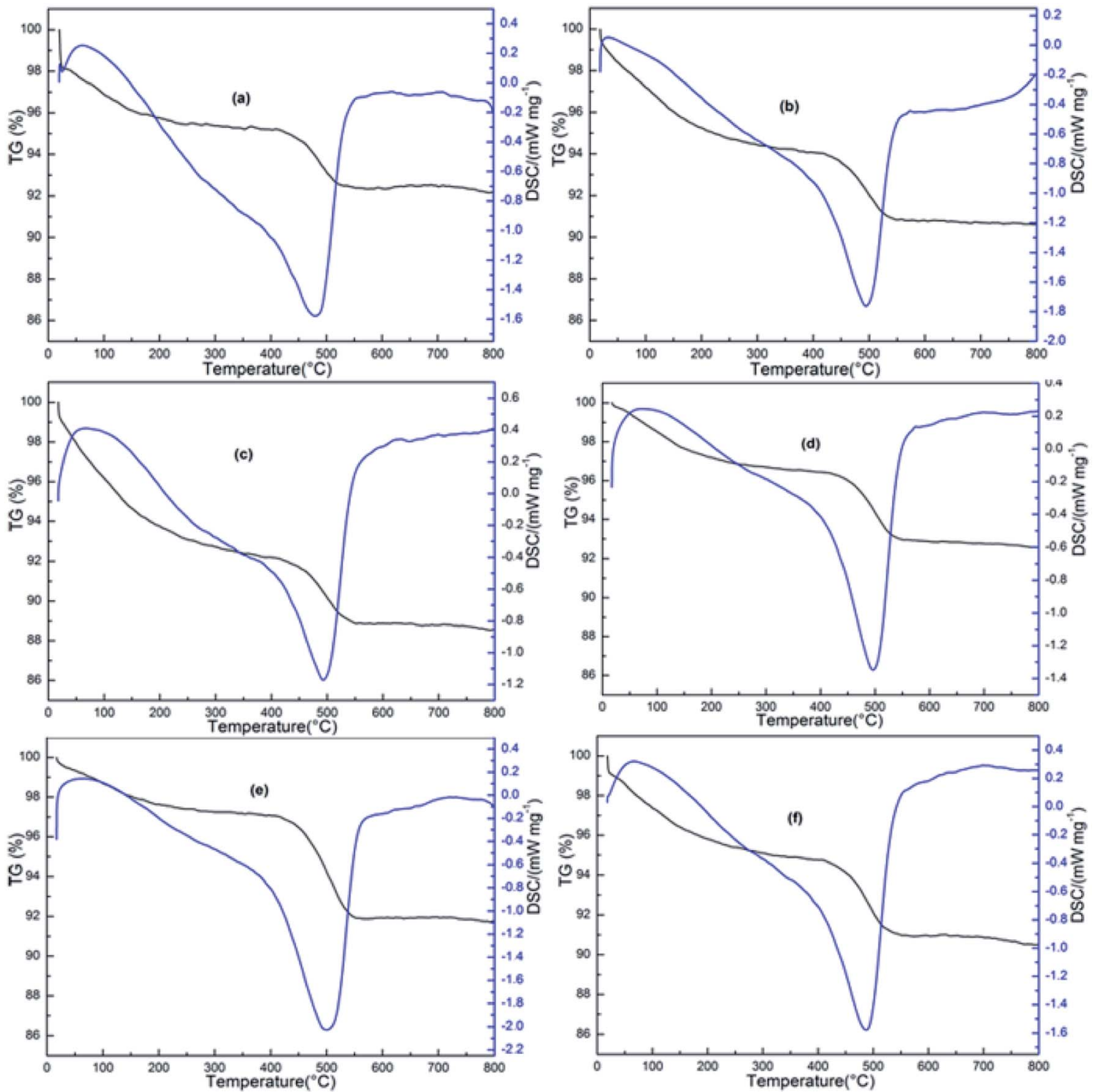

Fig. 11 TG-DSC curves of the spent catalysts at $580{ }^{\circ} \mathrm{C}$ reaction: (a) $3 \% \mathrm{Zn} / \mathrm{Al}_{2} \mathrm{O}_{3}$; (b) $5 \% \mathrm{Zn} / \mathrm{Al}_{2} \mathrm{O}_{3}$; (c) $7 \% \mathrm{Zn} / \mathrm{Al}_{2} \mathrm{O}_{3}$, (d) $10 \% \mathrm{Zn} / \mathrm{Al}_{2} \mathrm{O}_{3}$; (e) $15 \% \mathrm{Zn} /$ $\mathrm{Al}_{2} \mathrm{O}_{3}$ and the spent catalyst at $620{ }^{\circ} \mathrm{C}$ reaction: (f) $10 \% \mathrm{Zn} / \mathrm{Al}_{2} \mathrm{O}_{3}$. 
specific surface area $\left(163.3 \rightarrow 158.6 \mathrm{~m}^{2} \mathrm{~g}^{-1}\right)$ and pore volume $\left(0.43 \rightarrow 0.42 \mathrm{~cm}^{3} \mathrm{~g}^{-1}\right)$ of the regenerated $10 \% \mathrm{Zn} / \mathrm{Al}_{2} \mathrm{O}_{3}$ demonstrated the formed coke can be eliminated by regeneration process.

3.8.3. TG-DSC analysis. As we all know, coking is usually the main reason for catalyst deactivation in alkane dehydrogenation reaction. TG-DSC is a very efficient technique to analyze the coke amount and the characterization results are shown in Fig. 11. The TG curves presented downtrend with the increase of temperature, which could be divided into two stages. In the first stage, the weight losses in TG curves up to $300{ }^{\circ} \mathrm{C}$, ascribed to the loss of physically adsorbed water and impurities. The second stage, located in the $350-600{ }^{\circ} \mathrm{C}$, the losses was assigned to the removal of coke. The coke amount in the spent $3 \% \mathrm{Zn} /$ $\mathrm{Al}_{2} \mathrm{O}_{3}, 5 \% \mathrm{Zn} / \mathrm{Al}_{2} \mathrm{O}_{3}, 7 \% \mathrm{Zn} / \mathrm{Al}_{2} \mathrm{O}_{3}$ and $10 \% \mathrm{Zn} / \mathrm{Al}_{2} \mathrm{O}_{3}$ were $2.97 \%$, $3.22 \%, 3.29 \%$ and $3.45 \%$, respectively. Which similar coke amount was consistent with the same good stability of these ordered mesoporous catalysts. However, with increasing $\mathrm{Zn}$ content to $15 \%$, coke amount was markedly increased (5.19\%). Combined with the poor stability of $15 \% \mathrm{Zn} / \mathrm{Al}_{2} \mathrm{O}_{3}$ catalyst, the reason of serious deactivation may caused by more coke, which also indicated ordered meso-structure could effectively inhibited the formation of coke. ${ }^{38}$ Moreover, during $620{ }^{\circ} \mathrm{C}$ reaction temperature, the coke amount in the spent $10 \% \mathrm{Zn} / \mathrm{Al}_{2} \mathrm{O}_{3}$ catalyst increased to $3.79 \%$. It explained the stability decreased with the increase of reaction temperature.

3.8.4. The dehydrogenation-regeneration cycles. In order to examine the regenerative ability of the $10 \% \mathrm{Zn} / \mathrm{Al}_{2} \mathrm{O}_{3}$ catalyst, the five dehydrogenation-regeneration cycles were investigated (Fig. 12). By calculation, the initial isobutane conversion, isobutene selectivity and yield were $45.1 \%, 83.6 \%$ and $37.7 \%$ in the first cycle, respectively. With increasing reaction time, the catalytic activity decreased gradually. Following by $2 \mathrm{~h}$ regeneration of catalyst at $600{ }^{\circ} \mathrm{C}$ in air, the activity of catalyst was obviously restored, which affirmed coke was the main reason of catalyst deactivation. In the five cycle, the initial isobutane

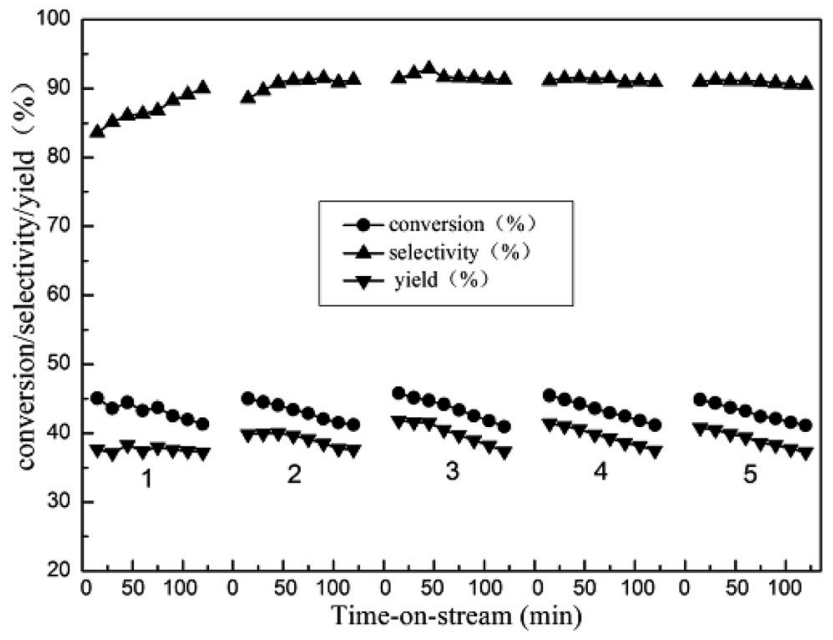

Fig. 12 The five dehydrogenation-regeneration cycles of isobutane dehydrogenation over $10 \% \mathrm{Zn} / \mathrm{Al}_{2} \mathrm{O}_{3}$ catalyst. Reaction condition: $T=$ $580^{\circ} \mathrm{C}, \mathrm{GHSV}=300 \mathrm{~h}^{-1}$. conversion, isobutene selectivity and yield were decrease slightly, indicated the high regenerative ability of the catalyst.

\section{Conclusions}

A series of $x \mathrm{Zn} / \mathrm{Al}_{2} \mathrm{O}_{3}$ materials with various $\mathrm{Zn}$ content were simply prepared via one pot EISA strategy and tested in isobutane dehydrogenation reaction. The obtained materials with $\mathrm{Zn}$ content up to $10 \%$ possessed well-ordered mesopore with large specific surface areas, big pore volumes and uniform pore size. Zinc species in these catalysts was highly dispersed on support surface or incorporated into framework, while $\mathrm{ZnO}$ crystal particles were observed with $23.8 \mathrm{~nm}$ size in the case of $15 \% \mathrm{Zn}$. It was found that these materials presented excellent catalytic activity. Note that the total acidic sites gradually increased, while the strong acidic sites decreased slowly with the increase of $\mathrm{Zn}$ content until $10 \%$. The decrease of strong acid sites is conducive to the promotion of isobutene selectivity and the weak and medium acidic sites played a role in isobutane conversion. In addition, the catalyst exhibited excellent stability and high regenerative ability, which demonstrated potential for commercial applications.

\section{Conflicts of interest}

There are no conflicts to declare.

\section{Acknowledgements}

The authors sincerely acknowledge the financial support from the National Natural Science Foundation of China (no. 21573260 and No. 21403255), Youth Innovation Promotion Association CAS (no. 2017460) and Jiangsu Science and Technology Program (no. BY2016048-01).

\section{References}

1 I. Gniot, P. Kirszensztejn and M. Kozłowski, Appl. Catal., A, 2009, 362, 67-74.

2 A. Feller, I. Zuazo, A. Guzman, J. O. Barth and J. A. Lercher, J. Catal., 2003, 216, 313-323.

3 Y. Tian, X. Liu, M. Rood and Z. Yan, Appl. Catal., A, 2017, 41, 1-9.

4 S. Al-Zahran, N. Elbashir, A. Abasaeed and M. Abdulwahed, Ind. Eng. Chem. Res., 2001, 40, 781-784.

5 L. Wan, Y. Zhou, Y. Zhang, Y. Duan, X. Liu and M. Xue, Ind. Eng. Chem. Res., 2011, 58, 4280-4285.

6 J. Zhang, D. Su, A. Zhang, D. Wang, R. Schlögl and C. Hebert, Angew. Chem., Int. Ed., 2007, 46, 7319-7323.

7 J. Grant, C. Carrero, F. Goeltl, J. Venegas, P. Mueller, S. Burt, S. Specht, W. McDermott, A. Chieregato and I. Hermans, Science, 2016, 354, 1570-1573.

8 J. H. B. Sattler, J. Ruiz-Martinez, E. Santillan-Jimenez and B. M. Weckhuysen, Chem. Rev., 2014, 114, 10613-10653.

9 J. Mu, J. Shi, L. France, Y. Wu, Q. Zeng, B. Liu, Li. Jiang, J. Long and X. Li, ACS Appl. Mater. Interfaces, 2018, 10, 23112-23121. 
10 H. Zhao, H. Song, J. Yang, J. Zhao, L. Yan and L. Chou, Catal. Sci. Technol., 2017, 15, 3256-3267.

11 S. Wang, K. Wang and X. Wang, Appl. Surf. Sci., 2016, 386, 442-450.

12 M. Cheng, H. Zhao, J. Yang, J. Zhao, L. Yan, H. Song and L. Chou, Microporous Mesoporous Mater., 2018, 266, 117-125.

13 J. Liu, A. Hong, N. He, G. Liu, C. Liang, X. Zhang and H. Guo, Chem. Eng. J., 2013, 218, 1-8.

14 Y. Sun and T. Brown, Int. J. Chem. Kinet., 2002, 34, 467-480.

15 G. Liu, J. Liu, N. He, C. Miao, J. Wang, Q. Xin and H. Guo, RSC Adv., 2018, 8, 18663-18671.

16 Z. Chen, A. Derking, W. Koot and M. van Dijk, J. Catal., 1996, 161, 730-741.

17 G. Wang, C. Li and H. Shan, Catal. Sci. Technol., 2016, 6, 3128-3136.

18 W. Wang, K. Zhang, Y. Yang, H. Liu, Z. Qiao and H. Luo, Microporous Mesoporous Mater., 2014, 193, 47-53.

19 S. M. Morris, P. F. Fulvio and M. Jaroniec, J. Am. Chem. Soc., 2008, 130, 15210-15216.

20 Q. Yuan, A. Yin, C. Luo, L. Sun, Y. Zhang, W. Duan, H. Liu and C. Yan, J. Am. Chem. Soc., 2008, 130, 3465-3472.

21 N. M. Schweitzer, B. Hu, U. Das, H. Kim and A. S. Hock, ACS Catal., 2014, 4, 1091-1098.

22 L. Xu, Z. Wang, H. Song and L. Chou, Catal. Commun., 2013, 35, 76-81.

23 M. Morris, P. Fulvio and M. Jaroniec, J. Am. Chem. Soc., 2008, 130, 15210-15216.
24 L. Xu, H. Song and L. Chou, Int. J. Hydrogen Energy, 2013, 38, 7307-7325.

25 D. Pan, W. Chen, F. Yu, S. Chen, X. Yan, X. Shi, B. Fan and R. Li, Mater. Lett., 2018, 224, 33-36.

26 X. Xiang, H. Zhao, J. Yang, J. Zhao, L. Yan, H. Song and L. Chou, Appl. Catal., A, 2016, 520, 140-150.

27 M. Kruk and M. Jaroniec, Chem. Mater., 2001, 13, 3169-3183.

28 Z. He, Y. Jiao, J. Wang and Y. Chen, Fuel, 2018, 212, 193-201.

29 A. Choi, J. Park, Y. Kang, S. Lee and Y. Kang, Phys. B, 2018, 537, 251-257.

30 W. Gu, X. Wu and J. Zhang, Mater. Sci. Semicond. Process., 2018, 81, 89-93.

31 S. Tamiyakul, W. Ubolcharoen, D. N. Tungasmita and S. Jongpatiwut, Catal. Today, 2015, 256, 325-335.

32 C. Yu, H. Xu, Q. Ge and W. Li, J. Mol. Catal. A: Chem., 2007, 266, 80-87.

33 H. Ham, M. H. Jeong, H. M. Koo, C. H. Chung and J. W. Bae, React. Kinet., Mech. Catal., 2015, 116, 173-189.

34 U. Rodemerck, E. V. Kondratenko, T. Otroshchenko and D. Linke, Chem. Commun., 2016, 52, 12222-12225.

35 S. Zhang, Y. Zhou, Y. Zhang and L. Huang, Catal. Lett., 2010, 135, 76-82.

36 Y. Ren, F. Zhang, W. Hua, Y. Yue and Z. Gao, Catal. Today, 2009, 148, 316-322.

37 M. Dixit, P. Kostetskyy and G. Mpourmpakis, ACS Catal., 2018, 8, 11570-11578.

38 L. Xu, Z. Miao, H. Song, W. Chen and L. Chou, Catal. Sci. Technol., 2014, 4, 1759-1770. 